\title{
ANESTHETIC EFFICACY OF 4\% ARTPHARMADENT VERSUS 2\% MEPECAINE-L FOR INFILTRATION ANESTHESIA IN EXTRACTION OF BADLY DECAYED LOWER FIRST PRIMARY MOLARS: A PILOT STUDY
}

\author{
Nadeen H. Hosny *, Randa Y. Abd Al Gawad ** and Mariam M. Aly ***
}

\begin{abstract}
Aim: The present study aimed to compare the efficacy of $4 \%$ Artpharmadent anesthetic solution compared to $2 \%$ Mepecaine- $\mathrm{L}$ anesthetic solution in extraction of badly decayed mandibular first primary molar for infiltration in children aged from 6 to 8 years.

Methodology: Twenty children with 20 badly decayed mandibular first primary molars indicated for extraction divided randomly into two equal groups $(n=10)$, group A received $4 \%$ Artpharmadent and group B received 2\% Mepecaine-L anesthetic solution for infiltration. Intraoperative pain, the need for supplemental injection during extraction, adverse effects following the anesthetic injection, and the clinical success of the treatment were evaluated for both groups.
\end{abstract}

Results: Both groups showed nearly similar results regarding intraoperative pain using WongBaker Face Pain Scale (WBFPS), and Sound, eyes, and motor (SEM) scale, regarding the need for supplemental injection during the extraction, and the adverse effects following the anesthetic injection (non-significant difference statistically).

Conclusions: Both the $4 \%$ Artpharmadent and 2\% Mepecaine-L are equally effective in controlling intraoperative pain during the extraction of mandibular molars and both are safe when used in children.

KEYWORDS: Artpharmadent, Mepecaine-L, Infiltration anesthesia, Extraction, Primary molars.

* Former internal resident, Pediatric Dentistry Department, Faculty of Dentistry, Cairo University, MSc Degree Candidate, Pediatric Dentistry and Dental Public Health Department, Faculty of Dentistry, Cairo University.

**A Associate Professor in Pediatric Dentistry and Dental Public Health Department, Faculty of Dentistry, Cairo University.

*** Lecturer in Pediatric Dentistry and Dental Public Health Department, Faculty of Dentistry, Cairo University. 


\section{INTRODUCTION}

One of the major challenges in pediatric dentistry is dental fear and anxiety (DFA). They are a common reason for avoiding dental treatment, which over time, may result in deteriorated oral health. Local anesthesia injection is the most anxiety-provoking factor for children during dental treatment that why treating children with minimal discomfort and pain has always been of paramount importance in pediatric dentistry ${ }^{(1,2)}$.

Effective pain control during dental procedures has been one of the important perquisites of painless dentistry. There are various methods to control pain among which the use of a local anesthetic agent is the most common technique in dental practice ${ }^{(3,4)}$.

Local anesthesia (L.A.) is the temporary loss of sensation in one part of the body through topical or injected agents by inhibiting the ionic influx of sodium within neural fiber without affecting the level of consciousness ${ }^{(5)}$.

Articaine, mepivacaine, and lidocaine are the most widely used anesthetic solutions in dental clinics. Several studies have claimed that articaine has a superior success rate to Lidocaine, which is considered the gold standard anesthetic solution. Mepivacaine is the third most widely used anesthetic solution in dentistry only after articaine and lidocaine ${ }^{(6,7,8)}$.

Many medical emergencies that occur in dental offices are brought on by a reaction from the administration of L.A., although the serious complications for the L.A. are rare in nature when the drug is administered carefully and within the recommended dosage, the adverse effects may occur but they are usually of a reversible and temporary nature. The most common adverse reaction following the anesthetic injection is the psychogenic response commonly known as syncope, or fainting ${ }^{(9,10)}$.

The present study aimed to compare intraoperative pain, clinical success, the need for supplemental anesthesia, and adverse effects during the extraction of badly decayed mandibular first primary molar using 4\% Artpharmadent and 2\% Mepecaine-L anesthetic solutions for infiltration in children aged from 6 to 8 years.

\section{SUBJECTS AND METHODS}

\section{Selection of Samples}

Child enrolled according to the following eligibility criteria set by Mittal et al. (2015) ${ }^{11}$.

\section{Inclusion criteria}

- Co-operative children aged from 6-8 years according to the Frankle scale.

- Children with mandibular first primary molar indicated for extraction due to root caries.

- Both sexes were included.

- Children having normal intellectual development

- Children attending their first dental visit.

- Healthy children with no systemic problems.

- Children's weight was more than $20 \mathrm{~kg}$.

\section{Exclusion Criteria:}

- Children with an acute or sub-acute dental abscess.

- Children with marked root or bone resorption.

- Children with a history of bleeding disorders or hypersensitivity.

- Patients who had taken analgesics or antibiotics in the 12-hours preceding the injection.

- Children whose parents refuse to sign the informed consent.

\section{Diagnosis}

\section{Personal and Medical History}

History was taken from the child and his parent including personal, medical, and dental history by 
the principal investigator, and was recorded in a specially designed diagnostic chart.

\section{Clinical examination}

The principal investigator performed an extraoral and intra-oral examination. The suspected tooth was examined for the presence of any pathosis and to evaluate the extension of proximal caries gingivally.

\section{Radiographic examination}

Preoperative periapical $\mathrm{x}$-rays were done on the suspected molar by the principal investigator to confirm the presence of root caries with no marked bone or root resorption.

\section{Randomization}

Selected cases were randomly assigned to intervention and control groups using simple randomization with allocation ratio $1: 1$. The third investigator generated a random sequence using computer software (http://www.random.org/). The allocation sequence was concealed from the first investigator in sequential numbered opaque sealed envelopes by the third investigator. The envelopes were numbered from 1 to 20 where each patient took an envelope in ascending order.

\section{Group A (Intervention group)}

Ten children received an infiltration injection of Artpharmadent (4\% Articaine hydrochloride with 1:100,000 epinephrine).

\section{Group B (Control group)}

Ten children received an infiltration injection of $2 \%$ Mepecaine-L (2\% Mepivacaine hydrochloride with 1:100,000 Levonordefrin).

\section{Blinding}

This research was a triple-blinded study, where the patient, the operator, and the outcome assessor were blinded. The labels on the anesthetic carpules were masked with an adhesive opaque paper and each carpule was handed by the third investigator to the first investigator after opening the patient envelope. The first investigator gave the L.A., and the outcome assessment was done by first and third investigator.

\section{Intra-operative procedures}

The dose was calculated according to the child's weight. For buccal infiltration, $1.5 \mathrm{ml}$ of the anesthetic solution was injected at the depth of the buccal vestibule within reflected mucosa between the roots of the first mandibular primary molar according to Nair et al. (2018) ${ }^{\mathbf{1 2}}$. The needle was inserted with its bevel directed toward the bone making angle $45^{\circ}$ with the buccal aspect of the jaw. The needle was inserted into the soft tissue until the bone was touched (within $2 \mathrm{~mm}$ ). The anesthesia was deposited slowly over 30 seconds.

For intrapapillary infiltration, $0.2-0.3 \mathrm{ml}$ of L.A. solution was injected one minute after the buccal infiltration in the mesial and distal interdental papilla. The needle was inserted at the buccal aspect of the papilla two mm apical to the tip of the papilla parallel to the occlusal plane. The L.A. solution was injected slowly over a period of 20 seconds while the needle advanced lingually. Blanching of the papilla was an indication of successful injection.

Lower primary molars forceps with two pointed beaks engaged the bifurcation at a right angle to the handles. A strong apical grip was done by the principal investigator using forceps followed by steady lingual and buccal movement with reasonable force until luxation occurred. The final movement to get the tooth out of the socket was directed outward and occlusal.

If the child complained of pain during the extraction procedure, supplemental anesthesia was administered $(1.5 \mathrm{ml}$ buccal infiltration and $0.2-0.3 \mathrm{ml}$ intrapapillary injection). The need for supplemental anesthesia was recorded as a secondary outcome. A sterile piece of cotton was 
added to the extracted area. The child was asked to bite on the piece of cotton firmly for at least 30 minutes.

\section{Assessment of the Outcomes}

\section{Pain assessment scales}

\section{Wong-Baker Face Pain Scale (WBFPS)}

Immediately after the extraction, the participants were questioned about the level of pain experienced during the extraction by selecting the picture of facial expression that best represented their experience. Each face has an assigned numerical value that was recorded.

\section{Sound, eye, and motor scale (SEM)}

The children's reactions during the extraction were evaluated based on the sound, eye, and movement of the children using SEM scale. Each category of SEM scale scored ranged from 1 (comfort) to 4 (severe discomfort). The total scores of the four categories were recorded and tabulated. The procedure was videotaped and the intraoperative pain using SEM scale was evaluated objectively by blinded two assessors. This was done after training and calibration between the assessors before the start of the study. To ensure the inter-examiner reliability between the first and second assessors, the Kappa test was done after the treatment value.

\section{The need for supplemental anesthesia}

If the child complained of pain during the extraction procedure, supplemental anesthesia was administered using $1.5 \mathrm{ml}$ buccal infiltration and $0.2-0.3 \mathrm{ml}$ intrapapillary injection. The need for supplemental anesthesia was recorded.

\section{Incidence of adverse reactions}

After extraction, the principal investigator observed any adverse reactions including syncope and vomiting. The children were asked after the extraction procedure if they were feeling nauseous or not.
Patients were dismissed after 30 minutes from the anesthetic injection, then contacted by telephone two hours after the anesthetic injection to determine whether any adverse reactions occurred or not.

\section{Criteria for Clinical Success: Shah, $(2018)^{13}$}

Successful completion of the planned dental treatment without the need for supplemental anesthesia. Lack of adverse events, such as medical (e.g. syncope, nausea, or vomiting), dental emergencies, or associated with anesthesia delivery (e.g. paresthesia).

\section{Data Management and Storage}

\section{Statistical analysis}

Data was tabulated and statistical analysis used in this study was Kolmogorov-Smirnov and ShapiroWilk tests to assess data normality, Independent Student t-test to compare age between study groups, Chi-square to compare the frequency of qualitative data, and Mann-Whitney test to compare pain assessment scales between study groups. The significance level was set at $p \leq 0.05$. Cohen's Kappa was performed to evaluate inter-examiner reliability of Sound, eyes, and motor scale values.

\section{RESULTS}

\section{Demographic data}

\section{Age distribution among the study sample}

The mean ages of the study sample were $6.8 \pm 0.9$ years old. The mean age for group A was $6.5 \pm 0.8$ years old, and the mean age for group B was 7.2 \pm 0.9 years old. There was no significant difference in age between both groups ( $p=0.094)$.

\section{Gender distribution among the study sample}

Half of the study subjects were males (50\%) and the other half were females $(50 \%)$. There was no significant difference in gender distribution between both groups ( $p=1.000)$. 


\section{Assessment of Intra-operative pain}

\section{Wrong-Baker Face Pain Scale (WBFPS)}

The median score of WBFPS for group A was three and the median score for group B was zero as shown in figure (1). Mann-Whitney test showed that there was no significant difference in WBFPS values between group A and group B $(p=0.079)$.

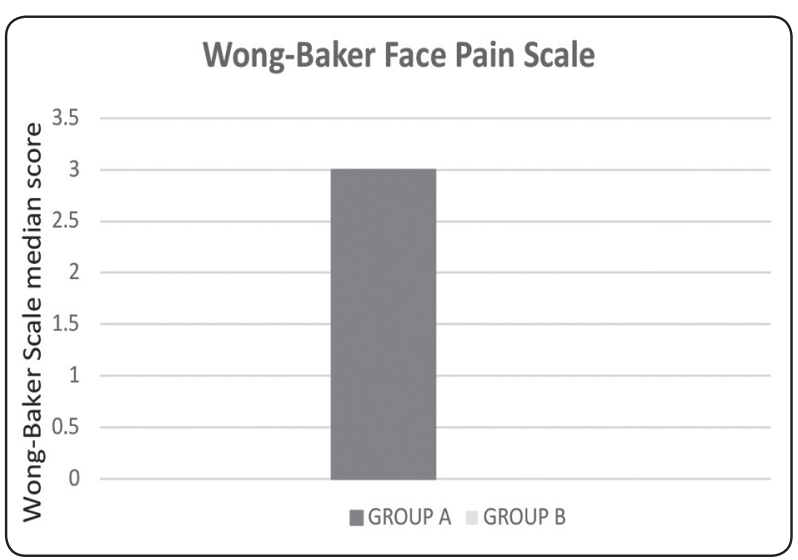

Fig. (1): Bar chart showing intraoperative pain assessment of WBFPS.

\section{Sound, Eye, and Motor Scale (SEM)}

Group A had been given a median score of (6) while group B had been given a median score of (5.5) as shown in figure (2). Mann-Whitney test showed that there was no statistically significant difference in SEM scale values between two groups with $(p=0.261)$.

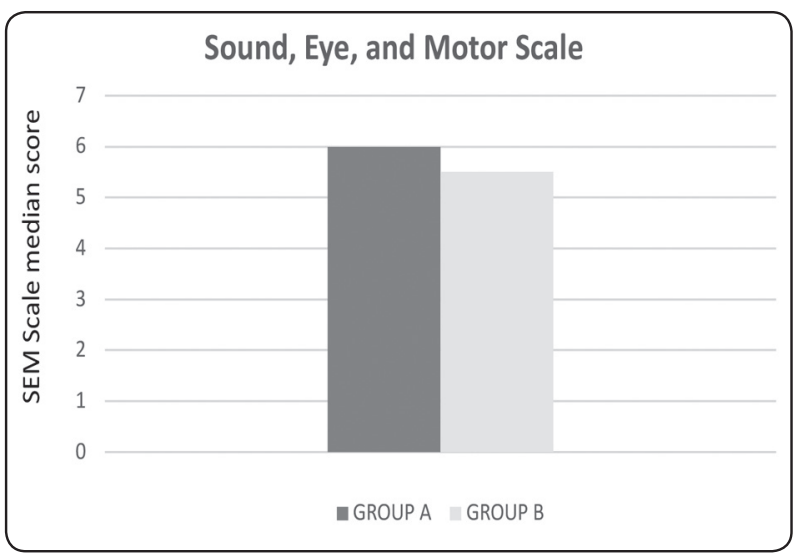

Fig. (2): Bar chart showing intraoperative pain assessment of SEM Scale

\section{Inter-examiner reliability}

Kappa test showed that there was an almost perfect inter-examiner agreement concerning SEM Scale values for both groups A and B as shown in table (1).

TABLE (1): Inter-examiner reliability regarding SEM scale.

\begin{tabular}{|c|c|c|c|c|}
\hline \multirow{2}{*}{} & \multicolumn{2}{|c|}{ Group A } & \multicolumn{2}{c|}{ Group B } \\
\cline { 2 - 5 } & Kappa & p-value & Kappa & p-value \\
\hline $\begin{array}{c}\text { inter-examiner } \\
\text { agreement }\end{array}$ & 1.000 & $<0.001 *$ & 0.851 & $<0.001 *$ \\
\hline
\end{tabular}

*significant at $p \leq 0.05$

\section{Correlations:}

Pearson's correlation coefficient showed that both WBFPS and SEM scale scores did not correlate either with age or gender as shown in table (2).

TABLE (2): Pearson's correlation coefficient (r) and $\mathrm{p}$-value for the correlation between intra-operative pain assessment scales and demographic characteristics

\begin{tabular}{|c|c|c|c|}
\hline \multirow{2}{*}{ WBFPS } & Variables & $\begin{array}{c}\text { Pearson's } \\
\text { Correlation (r) }\end{array}$ & p-value \\
\cline { 2 - 4 } & Age & -0.294 & $0.209 \mathrm{NS}$ \\
\hline \multirow{2}{*}{ SEM } & Gender & 0.252 & $0.283 \mathrm{NS}$ \\
\cline { 2 - 4 } & Age & -0.309 & $0.186 \mathrm{NS}$ \\
\hline
\end{tabular}

*NS: not significant at $p>0.05$

\section{The need for supplemental anesthesia}

In group A, only one patient required supplemental anesthesia representing $10 \%$. In group $\mathrm{B}$, one patient required supplemental anesthesia representing $10 \%$ with no statistically significant difference between the two groups $(p=1.000)$ as shown in table (3). 
TABLE (3): Frequency (n) and percentage (\%) for the need for supplemental anesthesia during dental treatment

\begin{tabular}{|l|c|c|c|c|c|}
\hline \multirow{2}{*}{} & \multicolumn{2}{|c|}{ Group A } & \multicolumn{2}{c|}{ Group B } & \multirow{2}{*}{ p-value } \\
\cline { 2 - 5 } & Yes & No & Yes & No & \\
\hline Need of supplemental anesthesia (n/\%) & $1(10 \%)$ & $9(90 \%)$ & $1(10 \%)$ & $9(90 \%)$ & \multirow{2}{*}{$1.000 \mathrm{NS}$} \\
\hline
\end{tabular}

*NS: not significant at $p>0.05$

TABLE (4): Frequency (n) and percentage (\%) for the adverse effects during dental treatment

\begin{tabular}{|cc|c|c|c|c|c|}
\hline \multirow{2}{*}{ Adverse Effects } & \multicolumn{2}{|c|}{ Group A } & \multicolumn{2}{c|}{ Group B } & \multirow{2}{*}{$p$-value } \\
\cline { 3 - 6 } & & Yes & No & Yes & No & \\
\hline Syncope & $(\mathbf{n} / \%)$ & $0(0 \%)$ & $10(100 \%)$ & $0(0 \%)$ & $10(100 \%)$ & $1.000 \mathrm{NS}$ \\
\hline Nausea & $(\mathbf{n} / \%)$ & $0(0 \%)$ & $10(100 \%)$ & $0(0 \%)$ & $10(100 \%)$ & $1.000 \mathrm{NS}$ \\
\hline Vomiting & $(\mathbf{n} / \%)$ & $0(0 \%)$ & $10(100 \%)$ & $0(0 \%)$ & $10(100 \%)$ & $1.000 \mathrm{NS}$ \\
\hline
\end{tabular}

*NS: non-significant at $p>0.05$

\section{The adverse effects during dental treatment}

None of the patients in group A and group B had any adverse effects including syncope, nausea, and vomiting during dental treatment with no statistically significant difference between the two groups ( $p=1.000$ ) as shown in table (4).

\section{The clinical success of the treatment}

The clinical success of the treatment showed that $90 \%$ of the cases in group A and group B fulfilled the criteria of clinical success of the treatment with no statistically significant difference between the two groups $(p=1.000)$.

\section{DISCUSSION}

Articaine, Mepivacaine, and Lidocaine are the most widely used anesthetic solutions in dental clinics. Evidence-based studies have claimed that articaine has a high success rate when used in children of 4 to 10 years of age ${ }^{(6,7)}$.

The newly introduced 4\% Artpharmadent was assigned as the intervention because it caught the eyes of the research team due to the advantage of being available in the local markets with reduced cost in comparison to the foreign articaine brands that have a higher cost and are not guaranteed to be available in local markets all the time. Also, articaine has the advantage of having high penetration capability due to the presence of thiopene ring in its chemical structure so achieving a rapid onset and faster dental anesthesia in comparison to mepivacaine ${ }^{(14,15,16)}$.

Two percent Mepecaine-L was chosen as a control group as it is one of the most widely used anesthetic solutions in dentistry and the most widely used anesthetic solution in Egypt due to its availability all the time and its low price. Moreover, it has several advantages over other solutions, such as a low vasodilatory effect and a $75 \%$ protein binding capability that is responsible for an increased duration of effectiveness ${ }^{(17)}$.

The buccal infiltration technique was chosen in the present study as it is effective for treating the mandibular deciduous dentition because of low bone mineral density. The infiltration technique is 
simple, comfortable, not technique sensitive, the injection site is easier to visualize, and the anesthetic solution is deposited directly in the area that will be treated. It also has fewer technical errors, less depth penetration of needle, reduced chances of needle stick injury, limited soft-tissue anesthesia outside the operation field, and shorter duration ${ }^{(18)}$.

Results of the baseline characteristics showed a similar distribution of the age and gender in both groups which was in agreement with Allegretti et al. (2016) $)^{19}$ and Gao and Meng, (2020) ${ }^{7}$. These may be attributed to randomization that ensured similar distribution of both known and unknown factors. Consequently, any potential effects of these parameters can be minimized or even neglected and the results obtained with both anesthetic solutions can be directly compared ${ }^{(20)}$.

The results in the current study show that there is no statistically significant difference in the intraoperative pain during the extraction procedure between group A (4\% Artpharmadent) and Group B (2\% Mepecaine-L) using the WBFPS scale. This result was consistent with the finding of Odabas et al. (2012) $)^{21}$ and Allegretti et al. (2016) ${ }^{19}$ who stated that there was no statistically significant difference between $4 \%$ articaine and $2 \%$ and $3 \%$ mepivacaine.

A contradicting result was reported by Azad et al. (2019) $)^{22}$ and Menditti et al. (2020) ${ }^{23}$ who stated that $4 \%$ articaine was superior in comparison to $2 \%$ mepivacaine. In contrast, Bortoluzzi et al. (2018) $)^{15}$ concluded that the overall performance of $2 \%$ mepivacaine was superior to $2 \%$ articaine, implying that $2 \%$ mepivacaine provides more effective anesthesia in terms of depth, extent, and duration.

This contradicting result can be explained by the unique characteristics that both solutions have, where the mepivacaine characterize by having a mild vasodilatory property that renders the mepivacaine having greater vasoconstriction, longer-lasting, and deeper anesthesia which may explain why mepivacaine performs better than articaine in some studies. While the Articaine characterizes by having a thiopene ring in its chemical structure causing high liposoloubiltiy and high penetration ability that leads to high potency and fast onset of action that makes the articaine superior to mepivacaine in other studies ${ }^{(7,15,16)}$.

Articaine was reported to be equally as effective or less effective when compared statistically to mepivacaine, which can be justified by similar relative efficacy, intrinsic activity, and the same intermediate category regarding the duration of action of the anesthesia ${ }^{(15,24)}$.

On the contrary, the intra-operative pain numerical data using the WBFPS scale showed better scores for group B (2\% Mepecaine-L) than group A (4\% Artpharmadent). This result was in agreement with Allegretti et al. (2016) ${ }^{19}$ who reported that $2 \%$ mepivacaine had better numerical values than $2 \%$ articaine despite being statistically insignificant. This can be justified by the high sensitivity of the WBFPS, highly individualized, and subjective events ${ }^{(15,25)}$.

Regarding the results of the intra-operative pain using the SEM scale, there was no statistically significant difference between both groups by first and second assessors. These results were in agreement with Wright et al. (1991) ${ }^{\mathbf{2 6}}$ who reported that there was no significant difference in pain assessment by SEM scale between $4 \%$ articaine and $2 \%$ mepivacaine during infiltration anesthesia for primary molars.

This result can be justified that articaine and mepivacaine located at the same intermediate category regarding the duration of action of anesthesia, also they have approximately similar efficacy and intrinsic activity as they have very close pKa (7.7 and 7.8) respectively, Also, the SEM scale is operator oriented not patient-oriented and the behavioral pain assessment scale may be affected by a non-painful stimulus like emotional suffering 
and by the culture of the patient which decreases the sensitivity and specificity of the behavioral pain scale ${ }^{(24,26,28)}$.

Kappa test declared that there was an almost perfect inter-examiner agreement concerning SEM Scale values for group A and group B which indicates a high reliability of the assessment. This can be justified by the calibration and training done for two examiners before the study ${ }^{(29)}$.

No correlation was found between intraoperative pain assessed by WBFPS and SEM scale and different demographic characteristics which in line with Mcentarfer et al. (2005) $)^{30}$ and Khatri and Kalra, (2012) $)^{31}$, and Abdelmoniem and Mahmoud, (2016) $^{32}$ who stated that the perception of the pain was similar in boys and girls at all age groups. On the contrary, Eltumi, and Tashani, (2017) ${ }^{33}$ reported that females seem to be more sensitive to experimentally induced pain in comparison with males, and the pain threshold increased between the ages of 5 and 18 years.

The results were explained by the fact that pain perception is a multidimensional experience with both sensory and cognitive components, results will vary depending on the environment in which the experiment takes place and the dimension of the pain being assessed ${ }^{(30)}$.

Regarding the results of the need for supplemental anesthesia, It showed that only one out of 10 patients in group $\mathrm{A}(4 \%$ Artpharmadent $)$ and one out of 10 patients in group B (2\% Mepecaine-L) required supplemental anesthesia during dental treatment. This in agreement with Gazal, (2018) ${ }^{16}$ and Menditti et al. (2020) ${ }^{23}$ who stated that there was a failure in dental anesthesia while using $2 \%$ mepivacaine and $4 \%$ articaine in some patients as they did not achieve $100 \%$ anesthetic success within the study and required additional anesthesia.

The need for supplemental anesthesia means a failure of the anesthetic solution to guarantee deep anesthesia for the mandibular teeth during the extraction procedure. A number of factors may contribute to the justification of failure of dental anesthesia, which may be related to either the patient or the operator. Patient-dependent factors may be anatomical, pathological, or psychological while operator-dependent factors may be the improper performance of the injection technique through the inaccurate placement of the needle in the correct place or the operator did not wait enough time for the anesthesia to act before starting the treatment ${ }^{(34)}$.

Regarding the presence of adverse effects in the current study, no adverse effects were associated with the anesthetic delivery in group A (4\% Artpharmadent) and group B (2\%Mepecaine-L). This is in agreement with Allegretti et al. (2016) ${ }^{19}$ who reported that there were no adverse effects related to the administration of L.A. in both $4 \%$ articaine and 2\% mepivacaine. On the contrary, Menditti et al. (2020) ${ }^{23}$ stated that adverse effects related to $2 \%$ mepivacaine were higher than $4 \%$ articaine.

This result may be explained by the adherence to recommended dosages to avoid adverse effects and systemic toxicity. Also, the articaine has the simplest and most rapid metabolism of the amides due to its carboxyl group ester linkage that easily breakdown by plasma cholinesterase ${ }^{(35,36)}$.

Regarding the results of the clinical success in this study, group A (4\% Artpharmadent) and group B (2\% Mepecaine-L) have the same success rate of 90\%. This agreeing with Allegretti et al. (2016) ${ }^{19}$ who reported that neither $4 \%$ articaine nor $2 \%$ mepivacaine achieved $100 \%$ success.

These results may be explained by the criteria of the clinical success in accordance to Shah, (2018) ${ }^{13}$ who stated that the need for supplemental anesthesia during the treatment is considered a failure that lowers the clinical success of the anesthetic solution. 


\section{CONCLUSIONS}

From the results of this study, the following can be concluded

1- Both 4\% Artpharmadent and 2\% Mepecaine-L can be used effectively in the control of pain during the extraction of mandibular molars.

2- No correlation was found between intraoperative pain assessed by WBFPS and SEM scale and different demographic characteristics like age and gender.

3- There was no statistically significant difference in the need for supplemental anesthesia in both groups.

4- No adverse reactions following the anesthetic injection were reported either from $4 \%$ Artpharmadent or 2\% Mepecaine-L.

\section{RECOMMENDATIONS}

Based on the results, the following could be recommended:

- Randomized clinical trials are recommended to evaluate intraoperative pain, the need for supplemental anesthesia during extraction, the adverse effects following the anesthetic injection, and clinical success of the treatment using 4\% Artpharmadent and 2\% Mepecaine-L anesthetic solutions including children at different age groups.

- Physiological pain measurements are recommended to assess intraoperative pain during extraction (heart rate, vagal tone, blood pressure, respiration rate, oxygen saturation rate, palmar sweating, and neuroendocrine responses).

- Other adverse effects than Syncope, nausea, and vomiting are recommended to be evaluated like (Pain at the site of injection, numbness, hypersensitivity, and alterations in heart rate or blood pressure).

\section{REFERENCES}

1. Abd Al Gawad, R., and Wassef, N. (2019): Effectiveness of two-stage versus one-stage injection in reducing discomfort during inferior alveolar nerve block in children, $\mathrm{J}$. Dent. Egy., 65(4): 3233-3239.

2. Dahlander, A., Soares, F., Grindefjord, M., and Dahllöf, G. (2019): Factors associated with dental fear and anxiety in children aged 7 to 9 years, Dent. J., 7(3): 1-9.

3. Hassan, S. (2017): HCL in Extraction of maxillary premolars for the Raj. Gan. Uni. Heal. Sci., 34(2): 1-22.

4. Baillargeau,C., Baillargeau,C.,Lopez-Cazaux, S., Charles, H., Ordureau, A., Dajean-Trutaud, S., Prud'homme, T., and Renard, E. (2020): Post-operative discomforts in children after extraction of primary teeth, Clin. Exp. Dent. Res.,102(10): 316-322.

5. Ogle, O. E., and Mahjoubi, G. (2012): Local anesthesia: Agents, techniques, and complications, Dent. Clin. Nor. Amer., 56(1): 133-148.

6. Arali, V., and Mytri, P. (2015): Anaesthetic efficacy of 4\% Articaine mandibular buccal infiltration compared to $2 \%$ Lignocaine inferior alveolar nerve block in children with irreversible pulpitis, J. Clin. Diag. Res. 9(4): 65-72.

7. Gao, X., and Meng, K. (2020): Comparison of articaine, lidocaine, and mepivacaine for buccal infiltration after inferior alveolar nerve block in mandibular posterior teeth with irreversible pulpitis, Brit. Dent. J., 228(8): 605-608.

8. Bahrololoomi, Z. and Rezaei, M. (2021): Anesthetic efficacy of single buccal infiltration of $4 \%$ articaine compared to routine inferior alveolar nerve block with $2 \%$ lidocaine during bilateral extraction of mandibular primary molars, a randomized controlled trial, J. Dent. Anesth. Pain Med., 21(1):61.

9. Kaufman, E., Goharian, S., and Katz, Y. (2000): Adverse reactions triggered by dental local anesthetics: a clinical survey., Anesth. Prog., 47(4): 134-138.

10. Sambrook, P., Smith, W., Elijah, J., and Goss, A.N. (2011): Severe adverse reactions to dental local anaesthetics: systemic reactions, Aust. Dent. J., 56(2): 148-153.

11. Mittal, M., Sharma, S., Kumar, A., Chopra, A., and Srivastava, D. (2015): Comparison of anesthetic efficacy of articaine and lidocaine during primary maxillary molar extractions in children., Ped. Dent., 37(3): 520-524.

12. Nair, M., Jeevanandan, G., and Mohan, M. (2018): Comparing the efficiency of $2 \%$ lidocaine and $4 \%$ articaine as a local anesthetic agent in children, Asian J. Pharm. clin. res., 11(5): 295-302. 
13. Shah, A. (2018): Comparing the effectiveness of articaine mandibular infiltration vs. lidocaine IANB in pediatric patients. Ph.D. thesis, University of Illinois, Chicago.

14. Ghavimi, M. A., Kananizadeh, Y., Hajizadeh, S., and Ghoreishizadeh, A. (2015): Overview of local anesthesia techniques, in a textbook of Adv. Oral. Max. Sur., $2^{\text {nd }}$ Edition, IntechOpen, London, 1-10.

15. Bortoluzzi, M. C., Smolarek, D. P., Cecato, R., Pochapski, M. T., and Chibinski, A. C. R. (2018): Anaesthetic efficacy of $4 \%$ articaine compared with $2 \%$ mepivacaine: a randomized, double-blind, crossover clinical trial, Inter. J. Oral. Max.Sur., 47(7): 933-939.

16. Gazal, G. (2018): Is Articaine more potent than Mepivacaine for use in oral surgery?, J. Oral. Max. Res., 9(3): 104-112.

17. Gazal, G., Alharbi, A. M., Al-Samadani, K. H., and Kanaa, M. D. (2015): Articaine and mepivacaine buccal infiltration in securing mandibular first molar pulp anesthesia following mepivacaine inferior alveolar nerve block: A randomized, double-blind crossover study, Saudi J. Anesth., 9(4): 397-403.

18. Tudeshchoie, D. G., Rozbahany, N. A., Hajiahmadi, M., and Jabarifar, E. (2013): Comparison of the efficacy of two anesthetic techniques of a mandibular primary first molar: A randomized clinical trial., Dent. Res. J., 10(5): 620-629.

19. Allegretti, C. E., Sampaio, R. M., Horliana, A. C. R. T., Armonia, P. L., Rocha, R. G., and Tortamano, I. P. (2016): Anesthetic efficacy in irreversible pulpitis: A Randomized clinical trial., Braz. Dent. J., 27(4): 381-386.

20. Gliklich, R. E., Dreyer, N. A., and Leavy, M. B. (2014): Analysis, interpretation, and reporting of registry data to evaluate outcomes., Agency Heal. Res. Qual., 3(5): 132-145.

21. Odabaş, M.E., Çınar, C., Deveci, C., and Alaçam, A. (2012): Comparison of the anesthetic efficacy of articaine and mepivacaine in pediatric patients: A randomized, double-blind study, Ped. Dent., 34(1): 42-45.

22. Azad, A.K., Kalam, A.B., George, A.N., Mary, A.N., Taufiq, M., Nur. M, Jamin, M., Hamizah, N., and Haron, L. (2019): Efficacy of 4\% Articaine and 2\% Mepivacaine without palatal injection in assessing pain during maxillary teeth extraction: A randomised clinical trial, J. Clin. Diag. Res., 13(12): 5-8.

23. Menditti, D., De Rosa A., Nucci L., Ribeiro Sobrinho, A.P., Laino L., Guglielmotti, M., d'Apuzzo F., Menditti, M., Boccellino M., and Rinaldi, B. (2020): Comparative study of the anesthetic efficacy of $4 \%$ articaine versus $2 \%$ mepivacaine in mandibular third molar germectomy using different anesthetic techniques, Ph.D. thesis, University of Campania Luigi Vanvitelli, Naples, Italy.
24. Malamed, S. F. (2019): Handbook of Local Anesthesia, $7^{\text {th }}$ Edition, Elsevier, Netherlands, 57-84.

25. Abdellatif, A. M. (2011): Pain assessment of two palatal anesthetic techniques and their effects on the child's behavior, Ped. Dent. J., 21(2): 129-137.

26. Wright, G. Z., Weinberger, S. J., Marti, R., and Plotzke, O. (1991): The effectiveness of infiltration anesthesia in the mandibular primary molar region., Ped. Dent., 13(5): 278-283.

27. Yekta-Michael, S., Stein, J. M., and Marioth-Wirtz, E. (2015): Evaluation of the anesthetic effect of epinephrinefree articaine and mepivacaine through quantitative sensory testing, Head. Face Med., 11(1): 142-150.

28. Bouajram, R. H., Sebat, C. M., Love, D., Louie, E. L., Wilson, M. D., and Duby, J. J. (2018): Comparison of selfreported and behavioral pain assessment tools in critically ill patients, J. Inten. Care. Med., 132(2): 122-134.

29. Adly, A.M. (2018): Reliability of light-induced fluorescence intraoral camera versus visual-tactile method in the assessment of marginal integrity of resin composite restorations: diagnostic invivo study, Masters Thesis, Cairo University, Egypt.

30. Mcentarfer, C., Dipirro, J., and Page, D. (2005): The effects of gender and aging on pain perception, Psi. Chi. J. Psyc. Res., 10(4): 145-149.

31. Khatri, A., and Kalra, N. (2012): A Comparison of two pain scales in the assessment of Dental Pain in East Delhi Children, ISRN. Dent., 32(4): 1-4.

32. Abdelmoniem, S. A. and Mahmoud, S. A. (2016): Comparative evaluation of passive, active, and passive-active distraction techniques on pain perception during local anesthesia administration in children, J.Adv.Res., 7(3): $551-556$

33. Eltumi, H. G., and Tashani, O. A. (2017): Effect of age, sex, and gender on pain sensitivity: A narrative review, Open Pain J., 10(1): 44-55.

34. Gazal, G. R., Fareed, W. M., Omar, E., Alolayan, A. B., Al-Zoubi, H., and Alnazzawi, A. (2017): Comparison of onset anesthesia time and injection discomfort of $4 \%$ articaine and $2 \%$ mepivacaine during teeth extractions, Saudi J. Anaesth., 11(2): 152-157.

35. Decloux, D. and Ouanounou,A. (2021): Local Anaesthesia in Dentistry: A Review , Intern. Dent. Jour., 71(2): 87-95.

36. Kumar, N., Nirmala, S. V. S. G., and Nuvvula, S. (2017): The Effectiveness of articaine and lidocaine single buccal infiltration versus conventional buccal and palatal injection using lidocaine during primary maxillary molar extraction, Anesth. Ess. Res.,11(1): 160-167. 